\title{
Comparison of the patient's satisfaction underwent penile prosthesis; Malleable versus Ambicor: Single center experience
}

\author{
Omer Bayrak, Sakip Erturhan, Ilker Seckiner, Mehmet Ozturk, Haluk Sen, Ahmet Erbagci \\ Department of Urology, Gaziantep University School of Medicine, Gaziantep, Turkey.
}

\begin{abstract}
Summary Objective: To compare the surgical results, complications, and satisfaction levels of patients who underwent malleable penile prosthesis implantation (M-PPI) and Ambicor penile prosthesis implantation (A-PPI).

Material and methods: One hundred forty two patients who underwent penile prosthesis implantation [M-PPI (PromedonTube $^{\circledR}$, Cordoba, Argentina): 81, and A-PPI (American Medical Systems, Minnesota, USA): 61] between 2013-2018 were evaluated retrospectively. Patients' age, body mass index, smoking history, etiological factors, modified "Erectile Dysfunction Inventory of Treatment Satisfaction (EDITS) Questionnaire" scores, shortening of the penis, and complications were recorded.

Results: The patients who performed A-PPI implantation were younger $(56.27 \pm 10.81$ vs. $51.47 \pm 11.79, p=0.009)$.

The EDITS scores of $31(38.2 \%)$ patients who underwent M-PPI and 44 (72.4\%) patients who underwent A-PPI were available. It was observed that the scores on the following questions were statistical significantly higher in the A-PPI group: "Overall, are you satisfied with your penile prosthesis?, How much of your expectations did penile prosthesis meet?, How often do you use your penile prosthesis?" ( $p=0.05$, $p=0.048, p=0.038$ ). No difference was observed between the groups in terms of the scores on the other three questions $(p=0.447, p=0.326, p=0.365)$. A $61.3 \%$ of patients in $M-$ PPI (19/31) group, and $56.8 \%$ of patients in A-PPI (25/44) group stated penile shortening $(p=0.417)$. Mean shortening was reported as $2.1 \pm 0.45 \mathrm{~cm}$, and $2.12 \pm 0.52 \mathrm{~cm}$, in $M-P P I$ and A-PPI groups, respectively $(p=0.90)$.

Conclusion:It is remarkable that the patients who underwent A-PPI experienced higher satisfaction with their prosthesis. Even though it has not been evidenced in the current literature data, patients who have had either M-PPI or A-PPI should be informed about the risk of penile shortening.
\end{abstract}

KEY WORDS: Erectile dysfunction; Penile prosthesis; Satisfaction; Complication.

Submitted 17 October 2019; Accepted 12 December 2019

\section{INTRODUCTION}

Erectile dysfunction (ED) is the second most common male sexual disorder after premature ejaculation and is defined as "a man's inability to achieve and/or maintain erection sufficient to have sexual intercourse, for at least six months" $(1,2)$. First and second-line conservative treatments, including medical therapies using either oral treatment or intracavernous injection as well as lifestyle changes, are the initial current methods suggested to patients with ED. Phosphodiesterase Type 5 inhibitors, intracavernous injections, intraurethral alprostadil and vacuum devices may cause treatment failure or lead the necessity to discontinue treatment in around $80 \%$ of the patients $(3,4)$.

Penile prosthesis implantation is recommended as a thirdline therapy in ED patients who do not respond to oral or non-surgical therapies or who are unable to accept such treatments for any reason (5). The surgical treatment has been modified many times in recent years to decrease the risk of complications, to reduce the mechanical dysfunction, and to increase patient/partner satisfaction.

Currently, penile prostheses are still commonly used as third line therapy in the treatment of $\operatorname{ED}(5,6)$.

In our study, we aimed to compare the surgical results, complications and satisfaction levels of patients who did not respond to first- and second-line therapies and who therefore underwent malleable penile prosthesis implantation (M-PPI) and Ambicor penile prosthesis implantation (A-PPI).

\section{MATERIAL AND METHOdS}

\section{Study participants}

Following the approval of the local ethics committee, 142 patients with ED who underwent penile prosthesis implantation in our clinic between 2013-2018 were evaluated retrospectively. It was found that 81 patients had M-PPI (Promedon-Tube ${ }^{\circledR}$, Cordoba, Argentina) and 61 patients had A-PPI (American Medical Systems, Minnesota, USA). Pre-operative informed consents were obtained from all patients.

Before the operations, the patients were given general information about the procedure and potential complications. Detailed information on M-PPI or A-PPI prosthesis types was provided to the patients. A-PPI implantation was primarily recommended to patients who were able to pay the price gap for PPI (cost of M-PPI: approximately USD 1000, cost of A-PPI: approximately USD 2000), were in a good mental state, and had good manual dexterity. Patients who had a history of unstable urethral or bladder neck stricture, abnormal psychiatric 
condition, a genital or systemic infection, perineal wounds, severe liver failure, uncontrolled hypertension or diabetes were excluded from the study.

\section{Efficacy and complication evaluations}

Patients' age, body mass index (BMI), smoking history, and etiological factors [diabetes mellitus (DM), coronary artery disease, hypertension, chronic kidney failure, neurological pathologies, radical prostatectomy and other pelvic surgeries] were recorded. The patients' scores for the modified "Erectile Dysfunction Inventory of Treatment Satisfaction (EDITS) Questionnaire" at the post-operative $6^{\text {th }}$ month, shortening of the penis, and complications (wound site infections, removal of prosthesis, hematoma, skin erosion and soft glans syndrome) were noted. The data on penile size was based only on the patient's perception.

The "Erectile Dysfunction Inventory of Treatment Satisfaction Questionnaire", and modified EDITS forms are reliable and validated questionnaires, which were created by Althof et al. to define satisfaction levels with ED therapies (7). The modified EDITS patient questionnaire is composed of six questions inquiring as level of satisfaction with ED treatment methods, level of expectations meet, suitability for continuous use, level of pleasure and confidence during sexual intercourse, and satisfaction of partners. Overall satisfaction is measured on a 5-point scale: 1- not satisfied at all, 3- partially satisfied and 5- very satisfied (7-9).

\section{Surgical procedure}

After spinal or general anesthesia, the pubic area of the patient was shaved and the genital area was washed with a povidone iodine solution for 10 minutes.

Intravenous cefazolin and gentamicin were administered for prophylaxis simultaneously. After placement of a 18 F Foley catheter, in a supine position, the corpora cavernosa were reached through a skin incision of approximately $3 \mathrm{~cm}$ from the penoscrotal region and a $2 \mathrm{~cm}$ bilateral corporotomy was performed. Afterwards, the sites where the penile prosthesis would be placed were created in the corpora cavernosa with Hegar dilators. Measurements were undertaken to choose a suitable size for the cylinder. During these procedures, the corpora cavernosa were irrigated with solutions containing gentamicin.

The prosthetic cylinders were inserted after the surgical site was

Table 1.

Demographic data.

Table 2. prepared. A pump was placed by creating a subdartos pouch in the scrotum in patients who underwent A-PPI. Following a hydraulic test, the corporotomies were closed with previously placed $2 / 0$ vicryl sutures. The procedure was completed by suturing the subcutaneous tissue and skin. We recommended to patients, to start sexual intercourse after six weeks from the surgical procedure.

\section{Statistical analyses}

The "SPSS 11 for Windows" software package was used for the statistical calculations and the data was expressed as arithmetic mean and standard deviation. The Chi-square distribution test and the Mann-Whitney U test were used to calculate categorical variables and compare mean values, respectively. The 95\% confidence interval ( $p<0.05$ ) was accepted as statistical significance.

\begin{tabular}{|c|c|c|c|}
\hline & $\begin{array}{l}\text { M-PPI } \\
(n=81)\end{array}$ & $\begin{array}{l}\text { A.PPI } \\
(n=61)\end{array}$ & p \\
\hline Age (year) & $56.27 \pm 10.81$ & $51.47 \pm 11.79$ & 0.009 \\
\hline BMI $\left(\mathrm{kg} / \mathrm{m}^{2}\right)$ & $27.19 \pm 2.43$ & $26.78 \pm 2.25$ & 0.211 \\
\hline Cigarette consumption (n, \%) & $65(80.2 \%)$ & $46(75.4 \%)$ & 0.490 \\
\hline Etiology $(n, \%)$ & $\begin{array}{l}\text { DM: } 57(70.3 \%) \\
\text { CAD: } 22(27.1 \%) \\
\text { HT: } 18(22.2 \%) \\
\text { CRF: } 2 \text { (2.5\%) } \\
\text { Neurological pathologies : } 3 \text { (3.7\%) } \\
\text { RP: } 7 \text { (8.6\%) } \\
\text { Other pelvic surgeries : } 6 \text { (7.4\%) } \\
\text { (TUR-prostate, orchiectomy, radical } \\
\text { cystectomy, urethroplasty) } \\
\text { Prosthesis replacement: } 4 \text { (4.93\%) }\end{array}$ & $\begin{array}{l}\text { DM: } 43(70.4 \%) \\
\text { CAD: } 5(8.2 \%) \\
\text { HT: } 9(14.75 \%) \\
\text { CRF: - } \\
\text { Neurological pathologies : } 1 \text { (1.6\%) } \\
\text { RP: } 5 \text { (8.2\%) } \\
\text { Other pelvic surgeries : } 8 \text { (13.1\%) } \\
\text { (TUR-prostate, orchiectomy, radical } \\
\text { cystectomy, urethroplasty) } \\
\text { Prosthesis replacement: } 5 \text { (8.1\%) }\end{array}$ & 0.569 \\
\hline
\end{tabular}

Comparison of patients' satisfaction according to Modified "Erectile Dysfunction Inventory of Treatment Satisfaction Questionnaire".

\begin{tabular}{|c|c|c|c|c|}
\hline $\begin{array}{l}\text { Modified EDITS } \\
\text { questionnaire }\end{array}$ & Grade of satisfaction & $\begin{array}{l}\text { M-PPI } \\
(n, \%)\end{array}$ & $\begin{array}{l}\text { A-PPI } \\
(\mathrm{n}, \%)\end{array}$ & p \\
\hline \multirow[t]{3}{*}{ Overall, are you satisfied with your penile prosthesis? } & I am not satisfied & $3(9.6 \%)$ & $1(2.3 \%)$ & $0.05^{*}$ \\
\hline & I'm partially satisfied & $5(16.1 \%)$ & $3(6.8 \%)$ & \\
\hline & I'm very satisfied & $23(74.2 \%)$ & $40(90.1 \%)$ & \\
\hline \multirow[t]{3}{*}{ How much of your expectations did penile prosthesis meet? } & Did not meet & $3(9.6 \%)$ & $1(2.3 \%)$ & $0.048^{*}$ \\
\hline & Partially met & $4(12.9 \%)$ & $2(4.5 \%)$ & \\
\hline & Fully met & $24(77.4 \%)$ & $41(93.1 \%)$ & \\
\hline \multirow[t]{3}{*}{ How often do you use use your penile prosthesis } & Almost never & $3(9.6 \%)$ & $1(2.3 \%)$ & $0.038^{*}$ \\
\hline & Sometimes & $10(32.2 \%)$ & $8(18.2 \%)$ & \\
\hline & Very often & $18(56.2 \%)$ & $35(79.5 \%)$ & \\
\hline \multirow[t]{3}{*}{ Is it easy for you to use penile prosthesis? } & Not easy & $3(9.6 \%)$ & $1(2.3 \%)$ & 0.447 \\
\hline & Partially easy & $3(9.6 \%)$ & $8(18.2 \%)$ & \\
\hline & Very easy & $25(80.6 \%)$ & $35(79.5 \%)$ & \\
\hline \multirow[t]{3}{*}{ Do you trust your ability of pleasure during intercourse? } & No & $3(9.6 \%)$ & $1(2.3 \%)$ & 0.326 \\
\hline & Partly & $2(6.4 \%)$ & $3(6.8 \%)$ & \\
\hline & Fully & $26(83.8 \%)$ & $40(90.1 \%)$ & \\
\hline \multirow[t]{3}{*}{ How is the satisfaction of your partner? } & Not satisfied & $2(6.45 \%)$ & $1(2.3 \%)$ & 0.365 \\
\hline & Partially satisfied & $2(6.45 \%)$ & $2(4.5 \%)$ & \\
\hline & Very satisfied & $27(87.1 \%)$ & $41(93.1 \%)$ & \\
\hline \multicolumn{5}{|l|}{$n:$ Number of patients. } \\
\hline \multicolumn{5}{|c|}{ EDITS: Erectile Dysfunction Inventory of Treatment Satisfaction Questionnaire. } \\
\hline \multicolumn{5}{|l|}{ M-PPI: Malleable penile prosthesis implantation. } \\
\hline \multicolumn{5}{|l|}{ A-PPI: Ambicor penile prosthesis implantation. } \\
\hline
\end{tabular}


Figure 1.

Comparison of patients' satisfaction who underwent malleable penile prosthesis implantation (M-PPI) and Ambicor penile prosthesis implantation (A-PPI).

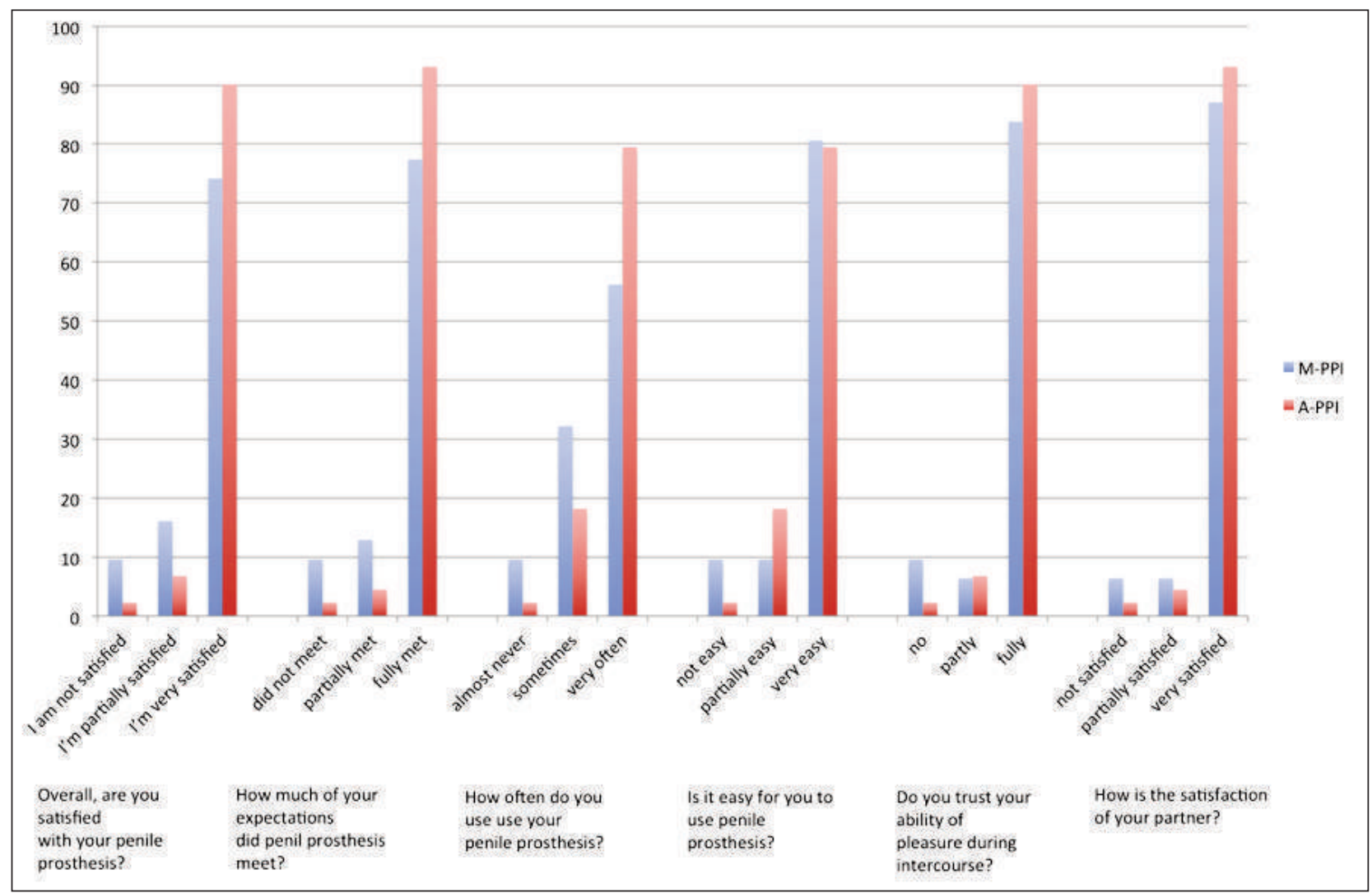

\section{RESULTS}

The mean age of patients who underwent implantation of Ambicor-PPI was lower than the mean age of patients who underwent implantation of M-PPI (51.47 \pm 11.79 vs. $56.27 \pm 10.81, p=0.009)$. Diabetes mellitus was as the most common etiological factor in both groups (70.3\% vs. $70.4 \%$ ). No differences were found between the two groups for body mass index and smoking history ( $\mathrm{p}=0.211, \mathrm{p}=0.490$, respectively) (Table 1 ).

Six-month scores of the EDITS forms were available in 31 (38.2\%) patients who had M-PPI implantation, and 44 (72.1\%) patients who had A-PPI. It was found that the scores for the following questions were statistical signifi-

Table 3.

Complications after penile prothesis implantation.

\begin{tabular}{|lccc|}
\hline & $\begin{array}{c}\text { M-PPI } \\
(\mathbf{n}=\mathbf{8 1})\end{array}$ & $\begin{array}{c}\text { A-PPI } \\
(\mathbf{n}=\mathbf{6 1})\end{array}$ & $\mathbf{p}$ \\
\hline Wound infection $(\mathrm{n}, \%)$ & $5(6.17 \%)$ & $4(6.55 \%)$ & 0.594 \\
\hline Removal of prosthesis $(\mathrm{n}, \%)$ & $3(3.7 \%)$ & - & 0.183 \\
\hline Hematoma $(\mathrm{n}, \%)$ & $1(1.2 \%)$ & $2(3.2 \%)$ & 0.394 \\
\hline Skin erosion due to tube kinging $(\mathrm{n}, \%)$ & - & $1(1.6 \%)$ & 0.430 \\
\hline Skin erosion due to pump ( $\mathrm{n}, \%)$ & - & $1(1.6 \%)$ & 0.430 \\
\hline Soft glans syndrome $(\mathrm{n}, \%)$ & $2(2.4 \%)$ & - & 0.324 \\
\hline Overall complications $(\mathrm{n}, \%)$ & $11(13.5 \%)$ & $8(13.1 \%)$ & 0.570 \\
\hline n: Number of patients. & & & \\
M-PPl: Malleable penile prosthesis implantation. & & & \\
A-PPl: Ambicor penile prosthesis implantation. & & & \\
\hline
\end{tabular}

cantly higher in favor of the A-PPI group: "Overall, are you satisfied with your penile prosthesis?, How much of your expectations did penile prosthesis meet?, How often do you use your penile prosthesis?" ( $\mathrm{p}=0.05, \mathrm{p}=0.048, \mathrm{p}=0.038$, respectively). However, no significant difference was observed between the two groups in terms of the scores for the following questions: "Is it easy for you to use penile prosthesis?, Do you trust your ability of pleasure during intercourse?, How is the satisfaction of your partner?" ( $p=0.447, p=0.326, p=$ 0.365 , respectively). Additionally, it was evaluated if the length of the patients' penis had shortened postoperatively or not. A 61.3\% (19/31) of patients in M-PPI group, and $56.8 \%(25 / 44)$ of patients in A-PPI group stated that the length of their penis had shortened ( $p=0.417)$.

Mean shortening was $2.1 \pm 0.45 \mathrm{~cm}$, and $2.12 \pm 0.52 \mathrm{~cm}$ in M-PPI group and A-PPI group, respectively $(\mathrm{p}=0.90)$ (Table 2, Figure 1).

There was no difference between the groups in terms of complications ( $p=0.569$ ); however, seven $(77.7 \%$ ) of nine patients who had wound site infection, and all (100\%) three patients whose prostheses were removed, had a history of DM (Table 3). Tube kinking and skin erosion occurred in a patient at postoperative 6th week, and pump erosion occurred in another patient at postoperative $8^{\text {th }}$ week. Both patients were re-operated in collaboration with a plastic surgeon, the tube and pump were fixed to deeper tissue and a skin flap was rotated. The wound sites of both patients recovered without complication. 


\section{Discussion}

In the literature, among the treatment options for ED, PPI has been reported to be the most successful surgical method with the highest level of satisfaction (10). Different prostheses have different advantages and disadvantages that may affect the satisfaction of the patient (11). M-PPI has a structure that enables bending downwards during dressing, and urination and upwards during intercourse. The superior characteristics of M-PPI are: low mechanical failure rates, more easier operative procedure, shorter operation time, and relative costeffectiveness. However, as a disadvantage, it may cause difficulties during endoscopic procedures which may become necessary at later time. Inflatable prostheses have cosmetic advantages and benefits such as increase in penile length, and girth that mimics a natural erection. The most important disadvantage of this prosthesis type is likelihood of mechanical damage (9).

Today, a three-piece PPI is recommended, and inserted as the first choice at many centers as its deflated appearance has a close to normal appearance, and it provides axial rigidity in various lengths. A-PPI constitutes almost $5 \%$ of all prostheses inserted (12). Two-piece prostheses are generally preferred by surgeons who do not wish to place a reservoir in the abdomen or the Retzius space (13). In our clinical practice, the patient's choice is taken into consideration after informing the patients of all penile prosthetic choices. However, one of the most important factors that play a role in the selection of an inflatable prosthesis is the cost. In present circumstances in our country, the approximate cost of a one-piece PPI is USD 1000, a two-piece PPI is USD 2000, and a three-piece PPI is USD 3000. Therefore, all patients referred to our clinic preferred MPPI or A-PPI. Another factor playing a role in the selection in our study is age. In particular, it has been seen that younger patients more often prefer A-PPI $(51.47 \pm 11.79$ vs. $56.27 \pm 10.81, \mathrm{p}=0.009$ ).

Patient satisfaction depends on multiple factors including pre-operative expectations, post-operative pain and edema, undesired side effects, functionality of prosthesis, ease of use and acceptability by partners (9). In our series, penile prosthesis implantation has high rates of satisfaction due to being able to ensure rapid, and full rigidity. Although our patients who underwent M-PPI implantation felt dissatisfied with constant rigidity in the first few days, this problem was accepted by patients over time. The most common side effects in patients who had an inflatable penile prosthesis implantation were pain, and discomfort associated with the pump in the scrotum, however, these patients learnt how to use the pump as a result of training provided by the clinic. None of the patients required the removal of the prosthesis as a result of dissatisfaction or inability to use. Scores for high satisfaction with penile prostheses $(90.1 \%$ vs. $74.2 \%, \mathrm{p}=0.05$ ), meeting the expectations $(93.1 \%$ vs. $77.4 \%, \mathrm{p}=0.048$ ) and more frequent sexual intercourse ( $79.5 \%$ vs. $56.2 \%, p=0.038)$ were significantly higher in the A-PPI group.

In their series in 2007, Lux et al. implemented A-PPI in 146 patients at two centers. The Authors reported the rate of mechanical failure as $0.7 \%$ in a mean follow-up period of 38 months. $95 \%$ of patients reported to have had little or no problem in learning how to use the prosthesis, and $84 \%$ of them expressed that they were able to achieve good or excellent rigidity during coitus with A-PPI. Patient and partner satisfaction were reported to be $85 \%$ and $76 \%$, respectively. It is noteworthy that Ambicor had a low rate of infection of $7 \%$, despite the fact that it did not contain any topical antimicrobial agents or Inhibizone (8). In previous studies reported by Levine et al., it was seen that the prosthesis functioned without any problem in follow-ups over 70 months in $97 \%$ of 131 patients who had A-PPI. More importantly, 93\% of patients and 90\% of partners stated that they would suggest A-PPI to other couples. In this study, particularly in examining partner experience, $76 \%$ of partners reported to experience more satisfaction with A-PPI during sexual intercourse (14). In the current study, higher satisfaction rates were reported in the M-PPI group and A-PPI group, of $87.1 \%$ and $93.1 \%$, respectively, although there was no statistically significant difference between the rates of satisfaction with intercourse $(\mathrm{p}=0.365)$.

The complication rates of Ambicor-PPI were reported as $7.6 \%, 2.1 \%$ and $9.5 \%$ in studies by Levine et al., Lux et al. and Gentile et al. $(8,14,15)$. Infection-related complications have been reported to be $2-3 \%$ in the existing literature (16). In our study, the overall complication rates were $13.5 \%$ in the M-PPI group, and $13.1 \%$ in the A-PPI group. The most feared complication, in particular with PPI, is infection (M-PPI: 6.17 vs. A-PPI: 6.55, p $=0.594)$. In the current study, in seven $(77.7 \%)$ out of nine patients occurred wound site infection, and all three patients (100\%) whose prostheses were removed had a history of DM. Moreover, in one patient with A-PPI, tube kinking occurred at 6 th week postoperatively, and pump erosion occurred in another patient at 8th week postoperatively. Both patients were operated in combination with a plastic surgeon, and a reconstruction was performed. The tube and pump were fixed to deeper tissue, and a flap was rotated. The wound sites of both patients recovered without any complication.

Additionally, this study assessed whether the size of the patients' penis had shortened compared to the period before implantation. A $61.3 \%$ of patients who had M-PPI (19/31), and 56.8\% of patients who had A-PPI (25/44) stated that the length of their penis had shortened ( $\mathrm{p}=$ $0.417)$. Mean shortening was $2.1 \pm 0.45 \mathrm{~cm}$, and $2.12 \pm$ $0.52 \mathrm{~cm}$ in M-PPI group and A-PPI group, respectively $(\mathrm{p}=0.90)$. Lux et al. also reported a mean shortening of 1.5 inches in the size of the penis for $70 \%$ of patients, in their study (8). On the other hand, in a study by Deveci et al., the stretched penile length was measured in patients who had undergone penile prosthesis surgery for the first time. Deveci reported that the A-PPI did not affect the stretched penile length at 1 and 6 month postoperative follow up (17)

The current study is one of the rare single-center investigations in the current literature comparing M-PPI and A-PPI over a large number of patients. However, its retrospective nature, the absence of randomization, and more EDITS scores available on the A-PPI group were significant limitations of our study. In addition, the data on penile shortening was based only on the patient's perception. 


\section{Conclusions}

It is remarkable that patients who underwent A-PPI experienced higher satisfaction with their prosthesis. Although no difference was observed between either PPIs in terms of complications, patients who have diabetes should be particularly warned against post-operative complications. Even though it has not been evidenced in the current literature, all patients who had either M-PPI or A-PPI should be informed about the risk of shortening of the penis.

\section{REFERENCES}

1. Lindau ST, Schumm LP, Laumann EO, et al. A study of sexuality and health among older adults in the United States. N Engl J Med. 2007; 357:762-74.

2. NIH Consensus Conference. Impotence. NIH Consensus Development Panel on Impotence. JAMA. 1993; 270:83-90.

3. Mulhall JP, Bella AJ, Briganti A, et al. Erectile function rehabilitation in the radical prostatectomy patient. J Sex Med. 2010; 7:1687-98.

4. Gontero P, Fontana F, Zitella A, et al. A prospective evaluation of efficacy and compliance with a multistep treatment approach for erectile dysfunction in patients after non-nerve sparing radical prostatectomy. BJU Int. 2005; 95:359-65.

5. Evans $C$. The use of penile prostheses in the treatment of impotence. Br J Urol. 1998; 81:591-8.

6. Minervini A, Ralph DJ, Pryor JP. Outcome of penile prosthesis implantation for treating erectile dysfunction: experience with 504 procedures. BJU Int. 2006; 97:129-33.

7. Althof SE, Corty EW, Levine SB, et al. EDITS: development of questionnaires for evaluating satisfaction with treatments for erectile dysfunction. Urology. 1999; 53:793-9.
8. Lux M, Reyes-Vallejo L, Morgentaler A, et al. Outcomes and satisfaction rates for the redesigned 2-piece penile prosthesis. J Urol. 2007; 177:262-6.

9. Kilicarslan H, Kaynak Y, Gokcen K, et al. Comparison of patient satisfaction rates for the malleable and two piece-inflatable penile prostheses. Turk J Urol. 2014; 40:207-10.

10. Rajpurkar A, Dhabuwala CB. Comparison of satisfaction rates and erectile function in patients treated with sildenafil, intracavernous prostaglandin E1 and penile implant surgery for erectile dysfunction in urology practice. J Urol. 2003; 170:159-63.

11. Anafarta K, Safak M, Bedük Y, et al. Clinical experience with inflatable and malleable penile implants in 104 patients. Urol Int. 1996; 56:100-4.

12. Henry GD, Karpman E, Brant W, et al. The who, how and what of real-world penile implantation in 2015: the PROPPER registry baseline data. J Urol. 2016; 427:195.

13. Abdelsayed GA, Levine LA. Ambicor 2-Piece Inflatable Penile Prosthesis: Who and How? J Sex Med. 2018; 15:410-5.

14. Levine LA, Estrada CR, Morgentaler A. Mechanical reliability and safety of and patient satisfaction with the Ambicor inflatable penile prosthesis: results of a 2 center study. J Urol. 2001; 166:9327.

15. Gentile G, Franceschelli A, Massenio P, et al. Patient's satisfaction after 2-piece inflatable penile prosthesis implantation: an Italian multicentric study. Arch Ital Urol Androl. 2016; 88:1-3.

16. Goldstein I, Newman L, Baum N, et al. Safety and efficacy outcome of mentor alpha-1 inflatable penile prosthesis implantation for impotence treatment. J Urol. 1997; 157:833-9.

17. Deveci S, Martin D, Parker M, et al. Penile length alterations following penile prosthesis surgery. Eur Urol. 2007; 51:1128-31.

\section{Correspondence}

Omer Bayrak

dromerbayrak@yahoo.com

Sakip Erturhan

mserturhan@yahoo.com

Ilker Seckiner

iseckiner@yahoo.com

Mehmet Ozturk

mehmetozturk000@hotmail.com

Haluk Sen

drhaluksen@gmail.com

Ahmet Erbagci

gantepuro@gmail.com

Department of Urology, Gaziantep University School of Medicine, Gaziantep, Turkey. 